\title{
Stressor-burnout relationship in software development teams
}

\author{
Sabine Sonnentag, ${ }^{*}$ Felix C. Brodbeck, Torsten Heinbokel and Wolfgang Stolte \\ Department of Psychology, University of Giessen, Otto-Behaghel-Strasse 10, D-35394 Giessen, Germany
}

\begin{abstract}
Burnout is an experience relevant not only to psychosocial professions, but also to technical work. It is predicted that in a technical profession work stressors are related to burnout and that this relationship is moderated by control at work, task requirements, and the quality of team interaction. In a sample of 180 software professionals from 29 software development projects, stressors were found to be positively related to burnout measures. Control at work, complexity at work, and openness to criticism within the team were all found to be significantly negatively related to lack of identification. Moderated regression analyses revealed that high cognitive requirements, high learning requirements, and low competition within the team enhanced the relationship between stressors and burnout.
\end{abstract}

There is little existing research pertaining to long-term effects of working conditions in technical professions such as software development or other fields of research and development (Curtis, Krasner \& Iscoe, 1988; Goldstein \& Rockert, 1984; Keenan \& Newton, 1987). Long-term effects can exist both in performance and strain areas. One issue linking these two areas is the burnout phenomenon. It is important to examine whether or not burnout occurs in technical professions, and if so, under what conditions, because the consequences of burnout may have an impact on the long-range adjustment of people within a company and on the teams in which they work.

\section{The concept of burnout}

The term burnout is usually applied to strain symptoms in psychosocial professions. Across various definitions, burnout is described as an individual's negative emotional experience leading to a chronic process (Maslach, 1982b; Shirom, 1989). It is experienced as exhaustion on a physical, emotional and cognitive level (Pines, Aronson \& Kafry, 1981; Shirom, 1989). Most definitions include withdrawal and decreasing involvement in the job, especially by persons who have been highly involved in their work.

If one uses a broad concept of burnout including physical fatigue and cognitive weariness (Shirom, 1989), it becomes evident that burnout symptoms also occur in technical professions. There are studies showing burnout to exist outside the field of psychosocial 
work, for example in engineers (Etzion, 1988) or secretaries (Nagy, 1985). These findings suggest that there are factors other than those inherent in a psychosocial job which may lead to burnout, such as the discrepancy between one's expectations concerning the work and one's experiences (Lauderdale, 1982), or stressors in the work situation (Carroll \& White, 1982; Maslach, 1982a; Perlman \& Hartman, 1982; Pines et al., 1981). In relation to this Jackson, Schwab \& Schuler (1986) have indicated that burnout is associated with involving and demanding work.

\section{Work characteristics in software development projects}

The possibility that burnout also occurs in software development is suggested by studies such as that of Kumashiro, Kamada \& Miyake (1989), which showed the stress scores of software engineers to be higher than those of other professionals. Factors in the work situation contributing to the overall high stress scores were pace of work and overtime. Fujigaki (1990) reported that especially during requirement analysis and debugging, i.e. under conditions of time pressure, strain level rose. In another study (Ivancevich, Napier \& Wetherbe, 1983, 1985), problems in communication, time pressure and overload were identified as typical stressors among software professionals. In addition, work in software development is characterized by high intellectual demands (Glass, Vessey \& Conger, 1992). It is very involving and requires permanent acquisition of knowledge and learning (Brodbeck, Sonnentag, Heinbokel, Stolte \& Frese, 1993; Walz, Elam \& Curtis, 1993). Rubin \& Hernandes (1988) reported high intrinsic work motivation in software professionals, which may make them prone to the development of burnout if they work in a stressful environment (Pines \& Aronson, 1988).

\section{Stressors, other work characteristics and burnout}

When analysing work situations three different work characteristics can be distinguished: regulation problems (i.e. stressors), control at work and work requirements (Frese \& Zapf, 1994). When work tasks are performed in teams - as is the case in software development -social interaction in the work-group is also an important feature of the work situation. It is expected that these various work characteristics are related to the experience of burnout.

We assume that burnout among software professionals is associated with the experience of stressors in their work situation. This relationship has been found to be true for various other professional groups, such as workers in human services (Shinn, Rosario, Morch \& Chestnut, 1984), teachers (Russell, Altmaier \& Velzen, 1987), or library media specialists (Fimian, Benedict \& Johnson, 1989). Weiss (1983) studied a sample of information system managers and reported relationships between job stress and psychological strain measures that were similar to those found in other professions. Thus, it can be hypothesized that work stress in software development projects is positively correlated with burnout.

Until now, the relationship of control at work and high work requirements to burnout has not been studied very extensively. However, existing studies have shown that control at work, job challenge, and tasks with a high motivation potential are negatively correlated with burnout (Friesen \& Sarros, 1989; Gaines \& Jermier, 1983; Landsbergis, 1988). 
Therefore, we hypothesize also that in software professionals control at work and high work requirements are negatively related to burnout.

The quality of team work is influenced by social interaction in the group. To the best of our knowledge, such interactions have not yet been studied in relation to burnout. The nearest empirical work deals with social support, showing negative relationships between supervisor and co-worker support and burnout (Etzion, 1984; Himle, Jayaratne \& Thyness, 1989; Russell et al., 1987). Gaines \& Jermier (1983) reported employees' emotional exhaustion in high stress organizations to be negatively correlated with work-group cohesiveness. Additionally, informal contacts with colleagues showed a negative relationship with emotional exhaustion and lack of personal accomplishment (Leiter, 1988). It can be assumed that in teams with a favourable social interaction, social support can be more easily provided. This leads to the hypothesis that a high quality social interaction within a team will be negatively related to team members' burnout.

\section{Moderator effects on the stressor-burnout relationship}

It can be assumed that the relationship between the previously discussed work characteristics and burnout is not exclusively direct. It is expected that control at work, work requirements, and quality of team interaction also have moderating effects on the stressor-burnout relationship.

The relationship between stressors and burnout in software professionals might be influenced by control at work because control enhances the opportunity of coping with a stressful situation (Frese, 1989) and also provides the possibility of leaving stressful situations. In studies of both blue-collar workers and psychosocial professionals, moderating effects of control on the relationship between stressors and psychosomatic complaints were found (Frese \& Semmer, 1991; Maslach, 1982a). Therefore, it is expected that control at work will reduce the relationship between work stress and burnout for software professionals as well. On the other hand, high requirements such as complexity at work do not offer chances to cope with stressors but put additional demands upon the individual (Frese, 1987). Therefore, we hypothesize that high requirements will increase the relationship between stressors and burnout.

Finally, we assume that high quality social interaction within a team mitigates the negative effects of stressors on burnout, in a way similar to the effect of social support (Etzion, 1984; Frese \& Semmer, 1991; House, 1981; LaRocco, House \& French, 1980; Pines et al., 1981).

\section{Summary of hypotheses}

The hypotheses can be summarized as follows:

1. Work stress is positively correlated with burnout.

2. Control at work, high requirements and a high quality of social interaction are negatively correlated with burnout.

3. Control at work reduces the relationship between stressors and burnout.

4. High requirements increase the relationship between stressors and burnout.

5. High quality social interaction within a team reduces the relationship between stressors and burnout. 


\section{Method}

\section{Sample}

The study was carried out at 29 software development projects from 19 German and Swiss companies. The projects studied produced software covering a broad application domain, including the administration of small and large companies, telephone and communication purposes, banks, insurance companies, traffic institutions, and process control software. Thirty-four per cent of the projects were studied during the early phases of software development (i.e. requirement analysis and software design), 28 per cent during coding and testing (including integration testing), and 38 per cent during delivery and maintenance. The mean project size was 10 members $(\mathrm{SD}=4.8$ ); an average of 74 per cent of the members in a given project participated in the study $(\mathrm{SD}=26.3)$.

The total sample size was 200 persons. With 186 subjects a three-hour structured interview was held. One hundred and eighty persons filled in a questionnaire. Because the questionnaires were filled in and returned after the interviews the return rate led to missing data. Full data were available for 166 persons. Of the subjects, 62.1 per cent were systems analysts and programmers, 14.8 per cent team leaders, 10.8 per cent subteam leaders, 9.9 per cent user representatives, and 2.5 per cent had other, mostly administrative tasks in the project. The subjects had spent an average of 5.7 years in software development projects. Most of them were male ( 75 per cent). The average age was 33 years.

\section{Measures}

All scales were in German. Means, standard deviations, reliabilities and intercorrelations for the scales are shown in Table 1 .

Burnout. There was no existing burnout scale which was well adapted for use with software developers. Therefore, a new 16-item measure was created, based on the Maslach Burnout Inventory (MBI; Maslach \& Jackson, 1986). In order to investigate the structure of this questionnaire a principal component analysis was performed. Since factor solutions break down easily in replications, the total sample was randomly divided into two subsamples. For each subsample a separate principal component analysis was computed. At first, the result was a stable three-factor solution for both subsamples'. The first factor was interpreted 'lack of identification', and is similar to low 'personal accomplishment' as described by Maslach \& Jackson (1984). The second factor included aspects of pressure and exhaustion, and the third factor, pressure and loss of a sense of quality.

For reliability reasons the second and third factors were combined. Again, a principal component analysis was performed, now forcing a two-factor solution on the data. The result was a stable two-factor solution in both subsamples (see Table 2). The first factor explained 28.6 per cent of the variance in the first subsample (31.4 per cent in the second subsample), and the second factor explained 15.1 per cent (15.6 per cent) of the variance. The new second factor was called 'perceived pressure'. Cronbach's alphas were .86 for the first and .62 for the second factor.

The intercorrelation between the two burnout factors is rather low (.10). Other studies have reported similar intercorrelations between lack of personal accomplishment and emotional exhaustion (Leiter, 1988; Maslach \& Jackson, 1981). Since lack of identification corresponds to low personal accomplishment, and perceived pressure to emotional exhaustion, it is obvious that our findings are in accordance with the already existing research on burnout.

Stressors. Stressors in the work situation were ascertained with a 20 -item questionnaire (Frese, 1988). The scale covers various sources of stressors: stressors in the work itself such as quantitative overload (e.g. I have too

'For the first subsample, the first analysis generated a four-factor solution, explaining together 56.9 per cent of the variance. However, the fourth factor consisted only of one item ('Someone who doesn't put his heart into a job like mine should switch to another profession'). Since this item reflects more an attitude than a burnout symptom, the item was excluded from further analysis. With the 15 remaining items a PCA was performed for the second subsample, forcing a three-factors solution on the data. The factor solution is consistent with that found in the first subsample, with all items showing factor loadings higher than .50. The three factors together explain 56.6 per cent of the variance. Tables for the two subsamples with factor loadings can be obtained on request from the first author. 


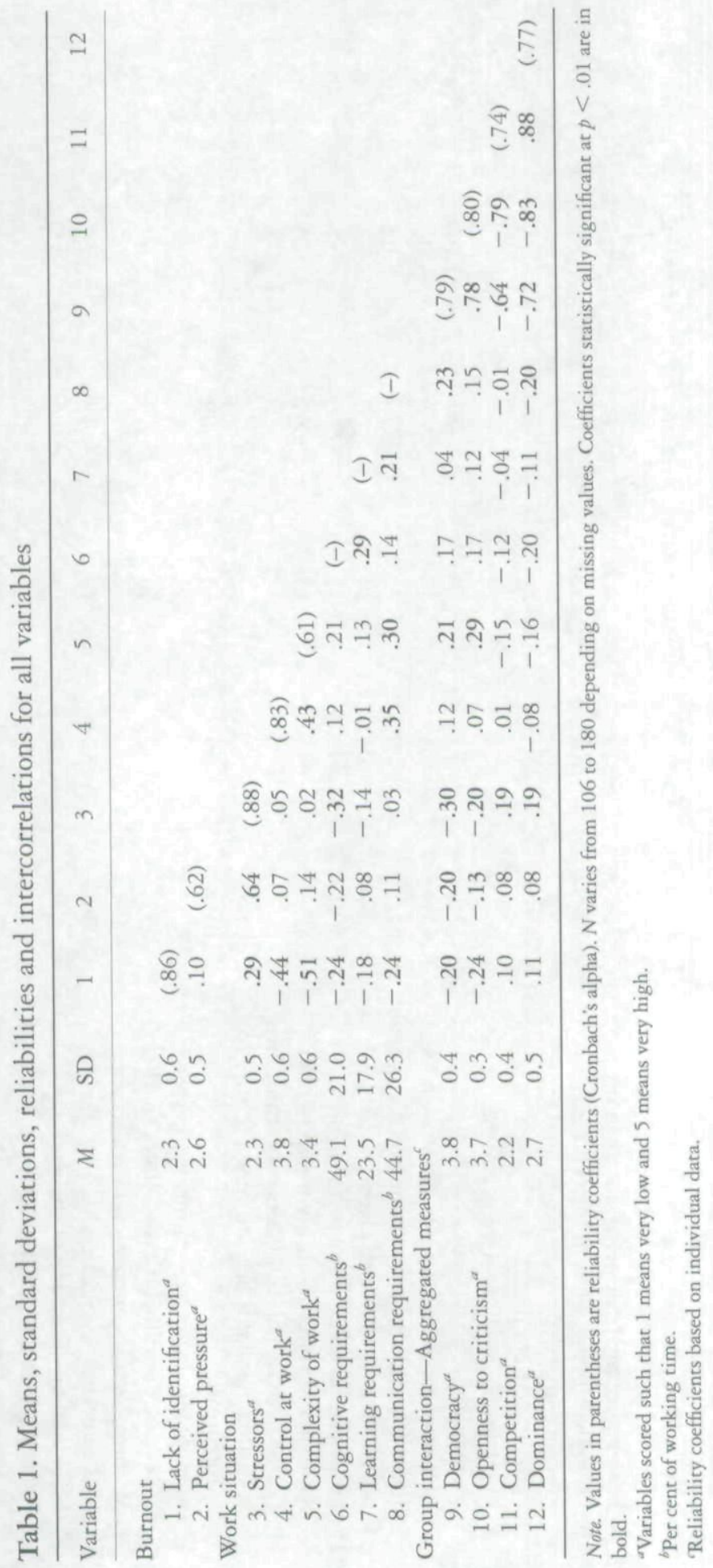




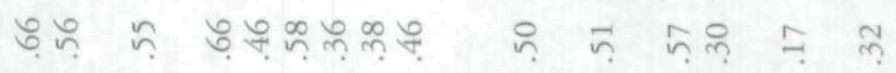

ㄷำ

कำ

ถุฒ

१ํา

?ำ

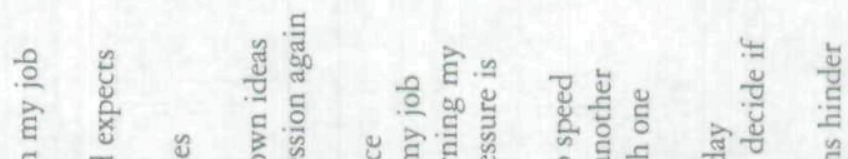

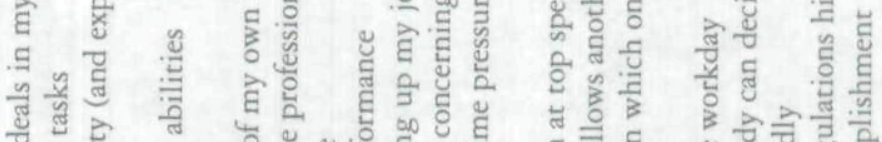

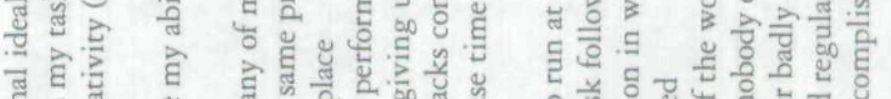

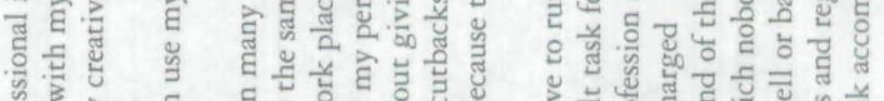

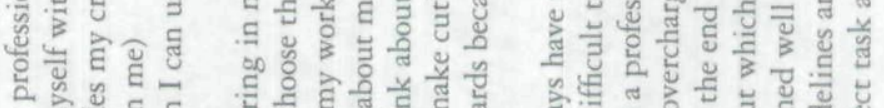

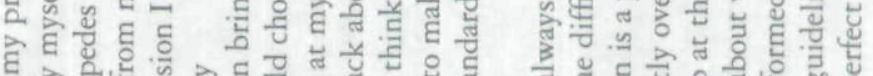

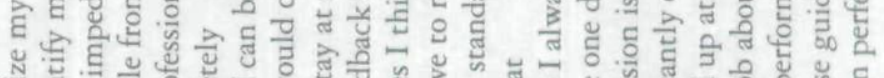

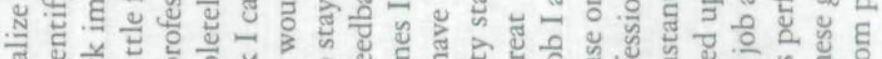
ङ 过 $\because$ 公 
much work'), stressors concerning performance and responsibility (e.g. 'I take too much responsibility for other people'), stressors concerning lack of influence (e.g. 'I am held accountable for things that I cannot influence'), stressors because of lack of career prospects (e.g. 'I have no opportunities for learning, increasing qualification, or development'), and stressors resulting from organizational policy (e.g 'Information comes too late or is too vague').

The validity of this stressor scale was examined by relating the stressor scores to an objective indicator of quantitative overload and time pressure. Therefore, from six to 12 months after the first investigation project, leaders and managers of 22 teams were asked if the intended schedule for intermediate products, milestones, and the final product had been kept (five-point Likert item). The project leaders' and managers' assessments of project delay was correlated $.47(\phi<.05)$ with the mean stressor scores in that project. In addition, the individual level correlation between the stressor scale and hours of overtime-considered a more objective measure-was $.26(\phi<.01)$. Although these correlations are not very high, they still indicate that perceived stressors correspond to objective indicators of a stressful situation. However, one would not expect higher correlations since the stressor scale also includes stressors other than quantitative overload, time pressure, and overtime.

Other work characteristics. Other work characteristics consisted of five variables: control at work, complexity of work and cognitive, learning and communication requirements. Control at work and complexity of work were ascertained by two questionnaire scales developed by Semmer (1984) and adapted to clerical work by Zapf (1991). Control at work consists of six items (e.g. 'Can you decide how you do your work?'). Complexity of work is a scale with four items (e.g. 'Do you get special tasks that are unusual and exceptionally difficult?'). Semmer \& Dunckel (1991) reported correlations of .50 and .54 for control at work and complexity of work with observational data in a sample of factory workers.

The cognitive, learning and communication requirements were assessed in an interview. The subjects were asked to give percentages of time spent for thinking (in contrast to performing routine tasks), for the acquisition of new knowledge, and for communicating, coordinating or cooperating. These three percentages are not distinct categories, of course, since it is possible to do two or more things at the same time, for example to acquire knowledge while communicating.

Quality of team interaction. The quality of social interaction in the team was measured with four scales based on items by Watson \& Michaelson (1988): democracy (six items; e.g. 'We encourage reticent members'), openness to criticism (six items; e.g. 'We take criticism as a valuable contribution to our individual work'), competition (five items; e.g. 'There are open hostilities among team members') and dominance (five items; e.g. 'Several team members tend to dominate discussions'). For the analyses, aggregated team measures were used based on the mean of the individual perceptions within each team. These measures reflected the average perceptions within the teams and can therefore be seen as more 'objective' measures (Frese \& Zapf, 1988).

Since the use of aggregated scores is only justified if there is a certain amount of perceptual agreement within the teams (James, 1982), inter-rater reliability was computed using a procedure proposed by James, Demaree \& Wolf (1984). For democracy the inter-rater reliability ranged from .86 to .98 (median $=.94)$, for openness to criticism from .75 to .98 (median $=.93$ ), for competition from .76 to .99 (median $=.95)$, and for dominance from .57 to .95 (median $=.87$ ). This indicates a high amount of agreement within the teams, thus justifying the use of aggregated scores.

\section{Data analysis}

The data were analysed by using separate moderated regression analysis for the two criterion variables, lack of identification and perceived pressure (Stone \& Hollenbeck, 1984; Zedeck, 1971). In the first step all main effects, i.e. stressors, control at work, complexity at work, cognitive, learning and communication requirements, and quality of team interaction measures, were entered into the equation. In the second step all interaction effects were entered into the equation. These interaction effects were computed as the product of stressors $X$ control at work, stressors $X$ complexity at work, stressors $X$ requirements, stressors $X$ team interaction measures. A significant increment of $R^{2}$ in this second step indicates the existence of moderator effects. Because the moderated regression approach is a conservative procedure (Clegg \& Wall, 1990), the significance level was fixed at .10 instead of .05 (as was, for example, done by LaRocco et al., 1980). 


\section{Results and discussion}

The results of the regression analyses are presented in Tables 3 and 4 . The tables show the multiple correlations, squared multiple correlations, the increment of $R^{2}$ when entering the interaction terms into the equation, corresponding $F$ values, partial correlations between predictors and burnout scores when controlling for all other predictors in the equation, regression coefficients, and the corresponding $t$ values. It can be seen from Table 3 that stressors, other work characteristics, and quality of team interaction accounted for 43 per cent of the variance in lack of identification, with stressors, control at work, complexity of work, and openness to criticism showing significant regression coefficients. This means that with respect to the burnout factor lack of identification, hypothesis 1 was supported by the data, and hypothesis 2 was partly supported.

When entering the interaction terms into the regression equation, an additional 7 per cent of the variance in lack of identification was explained. The significant positive interaction effect of stressors $\times$ cognitive requirements indicates that high cognitive requirements increased the relationship between stressors and lack of identification. This interaction effect is shown graphically in Fig. 1. Software professionals reporting high cognitive requirements revealed higher burnout scores if the level of stressors was high and lower burnout scores if the level of stressors was low than was the case for those with low cognitive requirements.

At first glance this result seems to contradict the negative zero-order correlation between cognitive requirements and lack of identification. However, in general, cognitive requirements are challenging and can, therefore, be conceptualized as a positive factor.

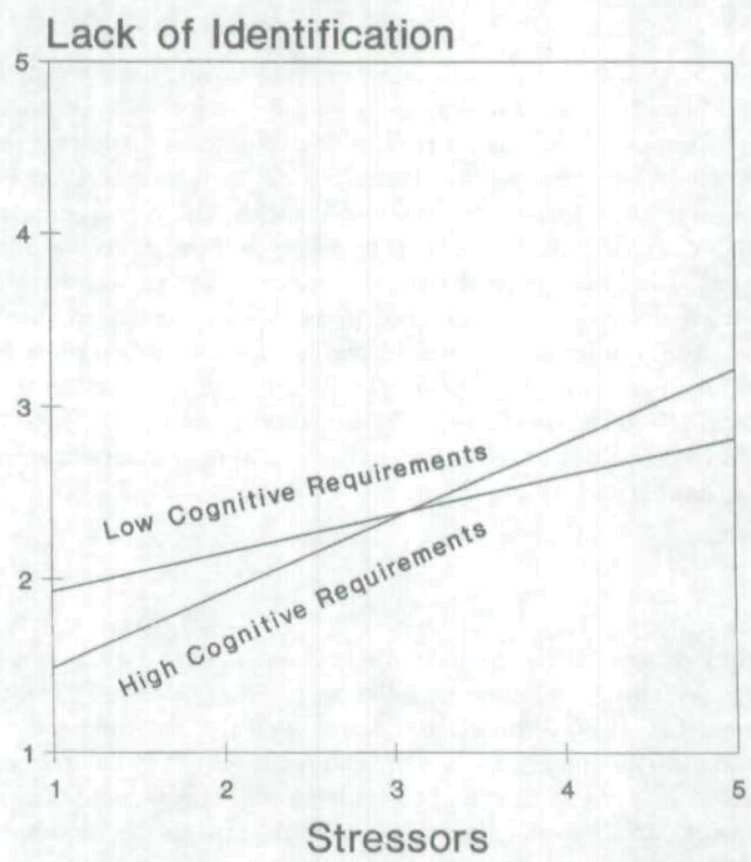

Figure 1. Moderator effect of cognitive requirements on the relationship between stressors and lack of identification. 


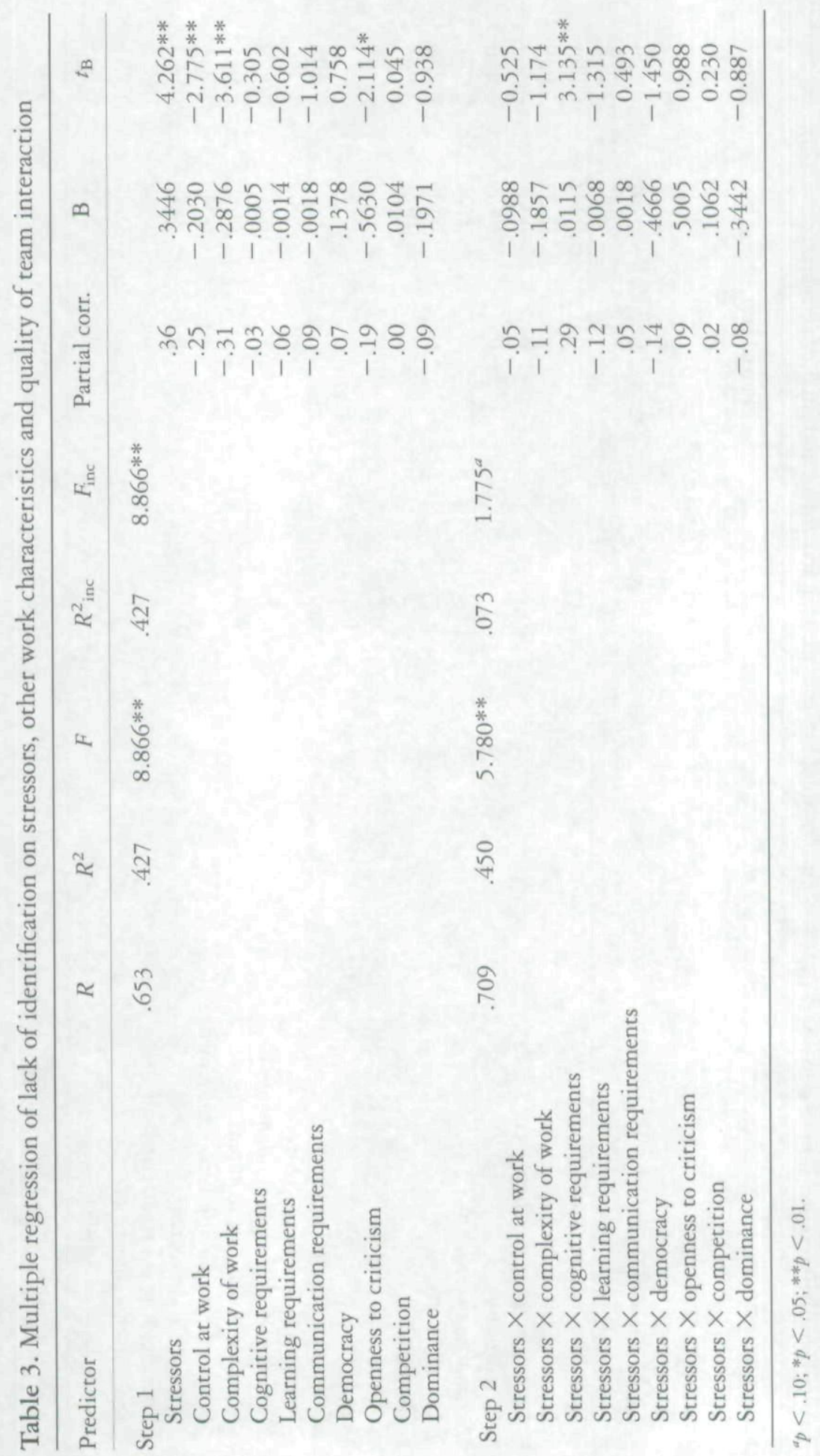


336

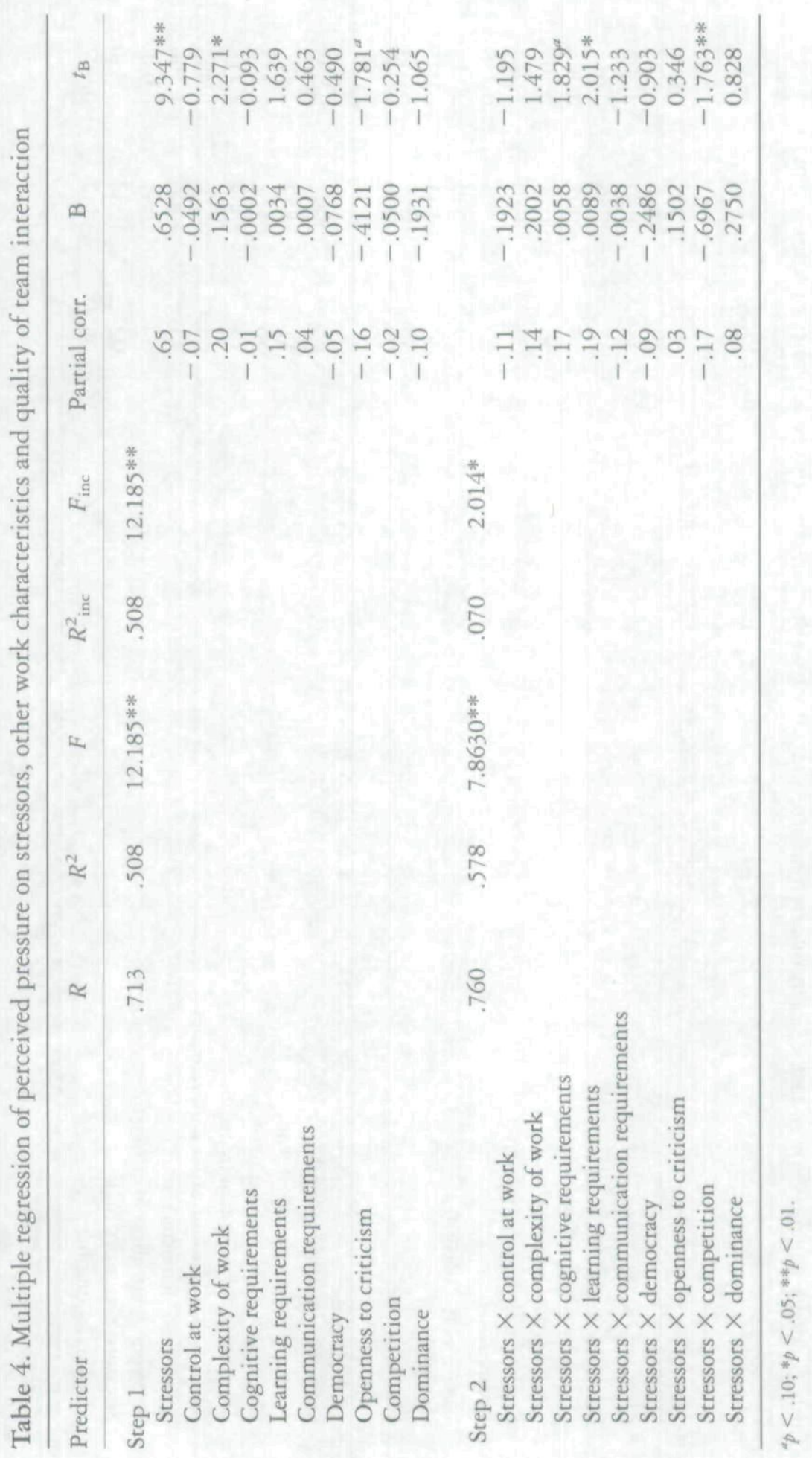


But, when stressors are high there may be too much challenge, resulting in high burnout scores. Thus, with respect to lack of identification, hypothesis 4 was partially supported by the data, while hypotheses 3 and 5 were not supported.

Table 4 shows that 51 per cent in the variance of perceived pressure was explained by stressors, other work characteristics, and quality of team interaction measures. Stressors showed the strongest relationship to this burnout factor. One reason for this pattern may be a conceptual overlap between stressors and perceived pressure (cf. Kasl, 1978). Another reason may be that the experience of perceived pressure is a clear outcome of stressors while lack of identification has several different 'causes'. Contrary to hypothesis 2, complexity was positively related to perceived pressure. This indicates that complexity in the work situation of software professionals is not only a favourable factor. High complexity goes hand in hand with identification with one's job, but is at the same time related to the experience of pressure. Additionally, the effect of openness to criticism on perceived pressure was marginally significant. Thus, the analysis shows that with respect to perceived pressure, hypothesis 1 was supported, while hypothesis 2 was partially contradicted.

When entering the interaction terms into the regression equation an incremental $R^{2}$ of .07 resulted. Again, the regression coefficient of the significant interaction effect of stressors $\times$ cognitive requirements revealed a positive sign. The same pattern was found for the interaction effect of stressors $\times$ learning requirements, indicating that high cognitive and high learning requirements enhanced the already strong relationship between stressors and perceived pressure. Thus, hypothesis 4 was partially supported by the data.

In addition, a significant interaction effect between stressors and competition was found. The negative sign of the regression coefficient indicates that for persons in teams with a low level of competition, the relationship between stressors and perceived pressure was stronger than for those working in high-competition teams. This finding is in direct opposition to hypothesis 5. One explanation for this result might be that in the case of a highly stressful situation the requirements related to positive team interactions and low competition (i.e. discussions, mutual understanding) might be an additional burden hindering coping with stressors. Another interpretation of this result can be derived from the concept of 'group think' (Janis, 1972), which says that highly cohesive groups produce strong group norms and therefore show less successful problem-solving behaviour when stress occurs ${ }^{2}$. This assumption was supported by the data: in this analysis, group cohesion was operationalized as the standard deviation of competition within each of the teams. This standard deviation was then correlated with the aggregated competition measures resulting in $r=.58(p<.01)$ at the team level. According to this operationalization, in low-competition teams little variability within the team was found, which can be seen as a sign of the 'group think' phenomenon, thus making it difficult to deal with stressful situations. Again, there was no empirical support for hypothesis 3, which predicted a mitigating effect of control at work on the relationship between stressors and burnout.

\section{Overall discussion}

This study found that in software development, work stressors are positively related to lack of identification and perceived pressure. This finding is in accordance with the results

${ }^{2}$ We would like to thank an anonymous reviewer for this interpretation. 
of studies in other professional fields (Etzion, 1984; Friesen \& Sarros, 1989; Russell et al., 1987). In addition, other variables were also found to have significant relationships with burnout, especially with lack of identification. Thus, burnout is not only associated with stressful situations but also with a lack of positive features in the work situation, such as control at work or openness to criticism within the team.

A further purpose of this study was to examine potential moderating effects. Cognitive and learning requirements showed enhancing effects, while competition reduced the negative effects of stressors. This pattern indicates that high requirements and low competition make a stressful situation even worse. The nature of the moderating effect found for competition seems to contradict the results of studies finding desirable moderating effects of social support (e.g. Etzion, 1984; Russell et al., 1987). However, it must be noted that in the present study quality of team interaction, not social support, was measured. Therefore, competition may be positive because one can individually deal with the problems at hand and shut out demands and discussions with others when stress is high.

Our cross-sectional design does not allow the testing of causal patterns. Moreover, the results found in questionnaire-based studies may be due to common method variance (Campbell \& Fiske, 1959; Frese, 1985; Kasl, 1986). Although it would be optional to study the stressor-burnout relationship on the basis of observational data using a longitudinal design, certain checks can be made within the framework of our study. Cognitive, learning and communication requirements were ascertained during an interview while burnout was assessed with a questionnaire scale. The zero-order correlations between job requirements and burnout were indeed lower than were some other correlations but some relationships were still significant and significant moderator effects were also found for cognitive and learning requirements. Thus, not all of them can be dismissed as the result of common method variance. However, we tend to agree that the correlation between stressors and perceived pressure may have been enhanced by common method variance. Zapf (1989) has shown in LISREL analyses that, although the use of questionnaire scales increases correlations between stressors and psychological impairment scales, these correlations cannot be completely accounted for by common method variance.

Another weakness of questionnaire studies lies in possible individual response biases leading to an overestimation of the correlations between two variables. In order to rule out this possibility, aggregated measures of quality of team interaction were used. Again, main and moderator effects were found, indicating that not all results were due to individual response biases.

Although it is difficult to provide conclusive answers to practical issues based on data from a cross-sectional study, there are practical implications. While we do not know the causal path, there were clear relationships between stressors, low control, low openness to criticism within the team and burnout. High requirements in the job were found to be negative when combined with high stressors. If further research shows this relationship to be due to causal effects, preventing burnout among technical professions would seem to require a reduction in the level of stressors because high cognitive and learning requirements are inevitable in many of these jobs.

Finally, the study showed burnout to be a relevant psychological strain variable in the technical field, so its consideration should not be restricted to the psychosocial professions. Our results may have implications for research on burnout in other areas. Since burnout may occur even where there is no contact with clients or with students, the 
burnout phenomenon may need a broader conceptualization with more attention being paid to working conditions that can be generalized across a broader range of professions.

\section{Acknowledgements}

This article is based on the project IPAS (a German acronym for 'Interdisciplinary Project about the Work Situation in Software Development'). The project was supported by a grant from the Work and Technology Fund of the Ministry of Research and Technology of the Federal Republic of Germany (No. 01 HK 319). The authors take responsibility for this publication.

The project IPAS consists of a computer science part (University of Marburg: Udo Bittner, Wolfgang Hesse, Johannes Schnath), a social science part (SPG Sozialwissenschaftliche Projektgruppe, Munich: Friedrich Weltz, Rolf Ortmann), and a work psychology part (University of Giessen: Felix C. Brodbeck, Michael Frese, Torsten Heinbokel, Sabine Sonnentag, Wolfgang Stolte). Special thanks are due to Michael Frese, Michael West, Jerilyn Lewter, and anonymous reviewers for their helpful comments on earlier drafts of this paper.

\section{References}

Brodbeck, F. C., Sonnentag, S., Heinbokel, T., Stolte, W. \& Frese, M. (1993). Tätigkeitsschwerpunkte und Qualifikationsanforderungen in der Software-Entwicklung. Eine empirische Untersuchung. Softwaretechnik-Trends, 13(2), 31-40.

Campbell, D. T. \& Fiske, D. W. (1959). Convergent and discriminant validity by the multitrait-multimethod matrix. Psychological Bulletin, 56, 81-105.

Carroll, J. F. X. \& White, W. L. (1982). Theory building: Integrating individual and environmental factors within an ecological framework. In W. S. Paine (Ed.), Job Stress and Burnout. Research, Theory and Intervention Perspectives, pp. 41-60. Beverly Hills, CA: Sage.

Clegg, C. \& Wall, T. (1990). The relationship between simplified jobs and mental health: A replication study. Journal of Occupational Psychology, 63, 289-296.

Curtis, B., Krasner, H. \& Iscoe, N. (1988). A field study of the software design process for large systems. Communications of the ACM, 31, 1268-1287.

Etzion, D. (1984). Moderating effect of social support on the stress-burnout relationship. Journal of Applied Psychology, 69, 615-622.

Etzion, D. (1988). The experience of burnout and work/non work success in male and female engineers. A matched-pairs comparison. Human Resource Management, 27, 163-179.

Fimian, M. J., Benedict, S. A. \& Johnson, S. (1989). The measure of occupational stress and burnout among library media specialists. Library and Information Science Research, 11, 3-9.

Frese, M. (1985). Stress at work and psychosomatic complaints: A causal interpretation. Journal of Applied Psychology, 70, 314-328.

Frese, M. (1987). A theory of control and complexity: Implications for software design and integration of computer systems into the work place. In M. Frese, E. Ulich \& W. Dzida (Eds), Psycbological Lssues of Human-Computer Interaction at the Work Place, pp. 313-337. Amsterdam: North-Holland.

Frese, M. (1988). Besser fuebren. Stressmanagement. Muenchen: Mensch und Arbeit.

Frese, M. (1989). Theoretical models of control and health. In S. L. Sauter, J. J. Hurrell Jr \& C. L. Cooper (Eds), Job Control and Worker Health, pp. 107-127. Chichester: Wiley.

Frese, M. \& Semmer, N. (1991). Stressfolgen in Abhaengigkeit von Moderatorvariablen: Der Einfluss von Kontrolle und sozialer Unterstuetzung. In S. Greif, E. Bamberg \& N. Semmer (Eds), Psychischer Stress am Arbeitsplatz, pp. 135-153. Goettingen: Hogrefe.

Frese, M. \& Zapf, D. (1988). Methodological issues in the study of work stress: Objective vs. subjective measurement of work stress and the question of longitudinal studies. In C. L. Cooper \& R. Payne (Eds), Causes, Coping and Consequences of Stress at Work, pp. 375-411. Chichester: Wiley.

Frese, M. \& Zapf, D. (1994). Action as the core of work psychology: A German approach. In H. C. Triandis, M. D. Dunnette \& J. M. Hough (Eds), Handbook of Industrial and Organizational Psychology, vol. 4, p. 271-340. Palo Alto, CA: Consulting Psychologists Press. 
Friesen, D. \& Sarros, J. C. (1989). Sources of burnout among educators. Journal of Organizational Behavior, 10, 179-188.

Fujigaki, Y. (1990). A study of mental workload of software engineers. In L. Berlinguet \& D. Berthelette (Eds), Work with Display Units 89, pp. 395-402. Amsterdam: Elsevier.

Gaines, J. \& Jermier, J. M. (1983). Emotional exhaustion in a high stress organization. Academy of Management Journal, 26, 567-586.

Glass, R. L., Vessey, I. \& Conger, S. A. (1992). Software tasks: Intellectual or clerical. Information and Management, 23, 183-191.

Goldstein, D. K. \& Rockert, J. F. (1984). An examination of work related correlates of job satisfaction in programmer/analysts. MIS Quarterly, 8, 103-115.

Himle, D. P., Jayaratne, S. \& Thyness, P. (1989). The effects of emotional support on burnout, work stress, and mental health among Norwegian and American social workers. Journal of Social Science Research, 13, 27-45.

House, J. S. (1981). Work Stress and Social Support. Reading, MA: Addison-Wesley.

Ivancevich, J. M., Napier, H. A. \& Wetherbe, J. C. (1983). Occupational stress, attitudes, and health problems in the information systems professional. Communications of the ACM, 26, 800-806.

Ivancevich, J. M., Napier, H. A. \& Wetherbe, J. C. (1985). An empirical study of occupational stress, attitudes and health among information systems personnel. Information and Management, 9, 77-85.

Jackson, S. E., Schwab, R. L. \& Schuler, R. S. (1986). Toward an understanding of the burnout phenomenon. Journal of Applied Psychology, 71, 630-640.

James, L. R. (1982). Aggregation bias in estimates of perceptual agreement. Journal of Applied Psychology, 67, 219-229.

James, L. R., Demaree, R. G. \& Wolf, G. (1984). Estimating within-group interrater reliability with and without response bias. Journal of Applied Psychology, 69, 85-98.

Janis, I. L. (1972). Victims of Groupthink. Boston: Houghton Mifflin.

Kasl, S. V. (1978). Epidemiological contributions to the study of work stress. In C. L. Cooper \& R. Payne (Eds), Stress at Work, pp. 3-48. New York: Wiley.

Kasl, S. V. (1986). Stress and disease in the workplace: A methodological commentary on the accumulated evidence. In M. F. Cataldo \& T. J. Coates (Eds), Health and Industry. A Bebavioral Medicine Perspective, pp. 52-85. New York: Wiley.

Keenan, A. \& Newton, T. J. (1987). Work difficulties and stress in young professional engineers. Journal of Occupational Psychology, 60, 133-145.

Kumashiro, M., Kamada, R. \& Miyake, S. (1989). Mental stress with new technology at the workplace. In M. J. Smith \& G. Salvendy (Eds), Work with Computers: Organizational, Management, Stress and Health Aspects, Pp. 270-277. Amsterdam: Elsevier.

Landsbergis, P. A. (1988). Occupational stress among health care workers: A test of the job demands-control model. Journal of Organizational Behavior, 9, 217-239.

LaRocco, J. M., House, J. S. \& French, J. R. J. Jr (1980). Social support, occupational stress, and health. Journal of Health and Social Behavior, 21, 202-218.

Lauderdale, M. (1982). Burnout: Strategies for Personal and Organizational Life. Austin, TX: Learning Concepts.

Leiter, M. P. (1988). Burnout as a function of communication patterns: A study of a multidisciplinary mental health team. Group and Organization Studies, 13, 111-128.

Maslach, C. (1982a). Burnout. The Cost of Caring. Englewood Cliffs, NJ: Prentice-Hall.

Maslach, C. (1982b). Understanding burnout: Definitional issues in analyzing a complex phenomenon. In W. S. Paine (Ed.), Job Stress and Burnout. Research, Theory and Intervention Perspectives, pp. 29-40. Beverly Hills, CA: Sage.

Maslach, C . \& Jackson, S. E. (1981). The measurement of experienced burnout. Journal of Occupational Behavior, 2, 99-113.

Maslach, C. \& Jackson, S. E. (1984). Burnout in organizational settings. In S. Oscamp (Ed.), Applied Social Psycbology Annual, vol. 5, pp. 133-153. Beverly Hills, CA: Sage.

Maslach, C. \& Jackson, S. E. (1986). Maslach Burnout Inventory. Manual, 2nd ed. Palo Alto, CA: Consulting Psychologists Press.

Nagy, S. (1985). Burnout and selected variables as components of occupational stress. Psycbological Reports, 56, 195-200. 
Perlman, B. \& Hartman, E. A. (1982). Burnout: Summary and future research. Human Relations, 35 , 283-305.

Pines, A. \& Aronson, E. (1988). Career Burnout. Causes and Cures. New York: Free Press.

Pines, A., Aronson, E. \& Kafry, D. (1981). Burnout, from Tedium to Personal Growth. New York: Free Press.

Rubin, H. I. \& Hernandez, E. F. (1988). Motivations and behaviors of software professionals. In E. Awad (Ed.), Proceedings of the 1988 ACM SIGCPR Conference, pp. 62-71. New York: ACM.

Russell, D. W., Altmaier, E. \& Velzen, D. (1987). Job-related stress, social support, and burnout among classroom teachers. Journal of Applied Psychology, 72, 269-274.

Semmer, N. (1984). Stressbezogene Taetigkeitsanalyse: Psychologische Untersuchungen zur Analyse von Stress am Arbeitsplatz. Weinheim: Beltz.

Semmer, N. \& Dunckel, H. (1991). Stressbezogene Arbeitsanalyse. In S. Greif, E. Bamberg \& N. Semmer (Eds), Psychischer Stress am Arbeitsplatz, pp. 57-90. Goettingen: Hogrefe.

Shinn, M., Rosario, M., Morch, H. \& Chestnur, D. E. (1984). Coping with job stress and burnout in the human services. Journal of Personality and Social Psychology, 46, 864-876.

Shirom, A. (1989). Burnout in work organizations. In C. L. Cooper \& I. T. Robertson (Eds), International Review of Industrial and Organizational Psychology, pp. 25-48. Chichester: Wiley.

Stone, E. F. \& Hollenbeck, J. R. (1984). Some issues associated with the use of moderated regression. Organizational Behavior and Human Performance, 34, 195-213.

Walz, D. B., Elam, J. J. \& Curtis, B. (1993). Inside a software design team: Knowledge acquisition, sharing, and integration. Communications of the ACM, 36, 63-77.

Watson, W. E. \& Michaelson, L. K. (1988). Group interaction behaviors that affect group performance on an intellective task. Group and Organization Studies, 13, 495-516.

Weiss, M. (1983). Effects of work stress and social support on information systems managers. MIS Quarterly, 7, 29-43.

Zapf, D. (1989). Selbst und Fremdbeobachtung in der psychologischen Arbeitsanalyse. Goettingen: Hogrefe.

Zapf, D. (1991). Stressbezogene Arbeitsanalyse bei der Arbeit mit unterschiedlichen Buerosoftwaresystemen. Zeitschrift fuer Arbeits- und Organisationspsychologie, 35, 2-14.

Zedeck, S. (1971). Problems with the use of 'moderator' variables. Psychological Bulletin, 76, $295-310$.

Received 23 March 1992; revised version received 16 March 1994 